Journal of Engineering and Science Research, 2 (1): 37-44, 2018

e-ISSN:2289-7127

CRMPPublications, 2018

DOI:10.26666/rmp.jesr.2018.1.7

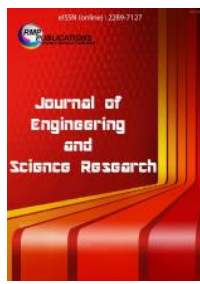

\title{
Stress Analysis of Engine Camshaft from Light Metal
}

\author{
Sharuddin Mohd Dahuri, Nor Hakimah Ahmad Subri and Dr Norashady Mohd Noor \\ Mechanical Engineering Department, Sultan Azlan Shah Politechnic, \\ 35950 Behrang, Perak Darul Ridzuan, Malaysia.
}

\begin{abstract}
This paper presents the structure and static model of engine camshaft analysis. For the purposes of this analysis, the finite element method is used. Camshaft is one of the critical components for effective and precise work of internal combustion engines. This camshaft rotates at high speed causing pressure and vibration in the system. Camshafts are also subject to varying fatigue burden due to cam plunger contact. These precise values are required to be determined to prevent failure in the camshaft. The objective of the project is to model and to perform pressure analysis on the camshaft machine. In this project the standard engine camshafts are modeled and analyzed using the CATIA V5R21 software respectively. This model is created by the basic requirements of the engine. It is done with an existing background, such as the power of acting on cam by means of a valve while running at maximum speed. Here the approach becomes fully CAE based. CAE-based approaches enrich Research and limit the time span. A study was conducted to predict the behavior of the different camshafts structure of the material using the finite three-dimensional pressure of the element. Four types of materials such as Steel, Titanium, Aluminum and Magnesium are taken into account. FEA Stress and maximum displacement decisions are calculated and compared to all of the above materials. The conclusion is to focus on the material suitable for the camshaft to reduce the maximum displacement and weight. Titanium materials become the best material for camshaft manufacturing based on analysis.
\end{abstract}

\section{Keywords - Camshaft, Stress,Displacement, Finite Element Analysis, CATIA.}

\section{INTRODUCTION}

\section{Camshafts}

Some may refer to the camshaft as a brain or engine heart. It determines when, how long, and how far the valve is open and closely related to the piston. It includes cam radars, journal bearings and core faces to block the Camshaft movement. The main function of the camshaft is to control the fuel valve and the poppet valve in the engine. The camshaft together with its components controls the opening and closing of two valves. Related parts are push rods, rocker arms, spring valves and tappets. The camshaft is driven with the help of a Crankshaft by time gear. Both the camshaft and the crankshaft determine the order of the shooting of the engine. The camshaft controls the operation of the valve train. [1]

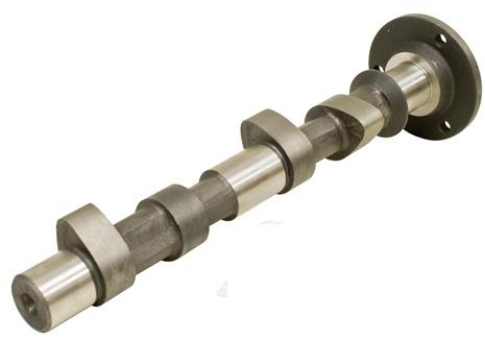

Fig 1: Conventional Camshaft. [2].

Valve trains include series including cams, followers, push rods, rocker arms, shafts, valves, springs, holders, rivets and keys. The complete system objective is to open and close the intake port and the exhaust port that leads to the combustion chamber. The main function of the camshaft is opening and closing the engine valve when needed. The camshaft design is such that the valve is open and closed at the right time. They are at a controlled rate by referring to the position of the piston.

Corresponding Author: Sharuddin Mohd Dahuri, Mechanical Engineering Department, Sultan Azlan Shah Politechnic, 35950 Behrang, Perak Darul Ridzuan, Malaysia. 0127475107 
There are two lobes per cylinder inside the camshaft. A lobe is to drive the intake valve and the other is to drive the exhaust valve. [3]

\section{Camshaft Specification}

An important concern for various engineers in the IC engine is to predict and extend the life of the bushing service. There are various variables in which the tensile strength of the bushing depends such as cam materials, elevator profiles and valve train configurations and various manufacturing processes. Much effort in the manufacturing industry is in progress where the grinding effect on camshaft service life is studied. It is found by the manufacturer that the quality and service life of the cam stem depends on the camshaft's ground (Abusive, moderate or gentle).

In general, the minimum requirements of camshaft are [3];

1. Have a good wear resistance; any signs of mark or wear show on the cams or supports will give a clear view of incompetent's part.

2. Have good rigidity strength; the camshaft can operate and win stand not more than $0.05 \mathrm{~mm}$ bending force and axial displacement bigger than $0.15 \mathrm{~mm}$.

3. Have a good toughness; the camshaft can operate and win stand load up to400 lb @ 7000rpm.

By referred to some info above, an analysis need to be done to determine the suitable light metal to replace the use of iron in a camshaft production specifically and engine as a whole. This is due to reduce the weight of engine to make it lighter and more efficient in power to weight value. The objective of this analysis is to determine what type of light metal that suited to replace iron in camshaft production. For his analysis, we only focus on the camshaft part, stress and displacement analysis and light metal such as Titanium, Aluminum and Magnesium.

\section{Light Metal}

Light metal is a relatively low density metal [4]. More specific definitions have been suggested; no one gets widespread acceptance. Magnesium, aluminum and titanium are the most important metals in commercial metals [5]. The density is $1.7,2.7$ and $4.5 \mathrm{~g} / \mathrm{cm} 3$ ranging from 19 to $56 \%$ of the density of the older metal structure [6], iron (7.9) and copper (8.9).

\section{Aluminium}

Aluminium is a chemical element with $\mathrm{Al}$ symbol and atomic number 13. It is a silvery, soft, non-magnetic, silvery metal in a boron group. With mass, aluminum forms about $8 \%$ of the earth's crust; it is the third most abundant element after oxygen and silicon and the most abundant metal on the scale, although it is less common in the coat below. Aluminum highly reactive aluminum metals whose native specimens are rare and confined to extreme environments. On the contrary, it is found to be combined in more than 270 different minerals [7].

Aluminum and its alloys are essential to the aerospace industry [8] and are important in the transportation and building industries, such as facade building and window frames [9]. Oxides and sulfates are the most useful compounds in aluminum [8].

Some general properties of aluminums' are;

Young Modulus: $7 \mathrm{e}+010 \mathrm{~N} \_\mathrm{m} 2$

Poisson Ratio: 0.346

Density: 2710 kg_m3

Yield Strength: $9.5 \mathrm{e}+007 \mathrm{~N} \_\mathrm{m} 2$

Price: $0.940 \mathrm{USD} / \mathrm{kg}$

\section{Magnesium}

Magnesium is a chemical element with $\mathrm{Mg}$ symbol and atomic number 12 . It is a shiny gray solid having a physical equation close to five other elements in the second column (group 2, or earth alkaline metal) from periodic table: all groups of 2 elements have electron configuration the same in outer shell and crystal structure of the same.

Magnesium is the eighth most abundant element in the crust [10] and the fourth most common element on Earth, forming $13 \%$ of the planet's mass and most of the planet's coat. It is the third most abundant element that is dissolved in seawater, after sodium and chlorine [11].

Magnesium occurs naturally only in combination with other elements, where it always has an oxidation state +2 . The free element can be artificially produced and highly reactive, it is shortly coated with a thin layer of oxide which partially blocks the reactivity. Irritant-free metal with special white light. The metal is now obtained primarily by the magnesium salt electrolysis derived from brine. Magnesium is valuable due to its mild combination and strength.

Some general properties of Magnesium are;

Young Modulus: 4.481e+010N_m2

Poisson Ratio: 0.35

Density: 1798 kg_m3

Yield Strength: 2.75e+008N_m2

Price: $2.260 \mathrm{USD} / \mathrm{kg}$

\section{Titanium}

Titanium is a chemical element with the Ti symbol and the atomic number 22. It is a glittering metal of silver, low density, and high strength. Titanium corrosion resistance in seawater, aqua region, and chlorine. 
This element occurs in some mineral deposits, especially rutils and ilmenites, which are widely distributed in crusts and lithosphere, and are found in almost all living things, bodies of water, rocks, and soil. [12] The metal was extracted from its primary mineral ore by the process of Kroll [13] and Hunter. The most common component, titanium dioxide, is a popular photo catalyst and is used in the manufacture of white pigments [14]. Other compounds include titanium tetrachloride (TiCl4), component of smoke screen and catalyst; and titanium trichloride $(\mathrm{TiCl} 3)$, which are used as catalysts in the production of polypropylene [12].

Titanium can be combined with iron, aluminum, vanadium, and molybdenum, among other elements to produce powerful and lightweight alloys for aerospace (jet engines, missiles and spacecraft), military, jewelry, mobile phones and other applications. [12].

The two most useful properties of the metal are the corrosion resistance and the strength ratio to the density, which is highest than any metallic element [15]. In a calm state, titanium is as strong as some steel, but less compact [16]. There are two forms of allotropic [17] and five natural isotopes of this element, 46Ti through 50Ti, with the most $48 \mathrm{Ti}(73.8 \%)$ [18]. Although they have the same number of valence electrons and are in the same group in periodic tables, titanium and zirconium differ in many chemical and physical properties.

Some general properties of Titanium are;

Young Modulus: $1.14 \mathrm{e}+011 \mathrm{~N} \_\mathrm{m} 2$

Poisson Ratio: 0.34

Density: 4460 kg_m3

Yield Strength: $8.25 \mathrm{e}+008 \mathrm{~N} \_\mathrm{m} 2$

Price: $3.770 \mathrm{USD} / \mathrm{kg}$

\section{INTRODUCTION TO CAD}

Computer Aided design (CAD) is the use of a computer system (or workstation) to assist in design creation, modification, analysis, or optimization [19]. CAD software is used to improve designer productivity, improve design quality, improve communication through documentation, and to create database for manufacturing [19]. CAD outputs are often electronic files for printing, machining, or other manufacturing operations. The CADD term (for Computer Assisted Design and Roll) is also used [20].

Its use in designing an electronic system is known as electronic design automation, or EDA. In mechanical design it is known as mechanical design automation (MDA) or computer help draft (CAD), which includes the process of creating technical drawings with the use of computer software [21].
CAD can be used to designate curves and numbers in two-dimensional space (2D); or curvature, surface, and solid in three-dimensional space (3D) [22].

CAD is an important industrial art widely used in many applications, including automotive industry, shipbuilding, and aerospace, industrial design and architecture, prosthetics, and more. Due to its exceptional economic importance, CAD has become a major mover for research in geometry of calculations, computer graphics (both hardware and software), and discrete geometry differences [23].

\section{INTRODUCTION TO FEA}

The finite element method (FEM) is a numerical method for solving engineering problems and mathematical physics. It is also referred to as finite element analysis (FEA). Common areas of interest include structural analysis, heat transfer, fluid flow, mass transport, and electromagnetic potential. Analytical solutions of these problems generally require solutions to the problem of boundary values for partial differential equations. The formulation of the finite method of the problem element produces an algebraic equation system. The method generates an unknown value estimate on the number of discrete points above the domain. [24] To solve this problem, it divides big problems into smaller, easier parts called finite elements. The simple equation of modeling these finite elements is then installed into a larger system of equations that model the whole problem. FEM then uses the variation method of variation calculus to approach the solution by minimizing the associated error function.

\section{INTRODUCTION TO CATIA}

CATIA is a multi-platform software suite for computer aided design (CAD), computer manufacturing (CAM), PLM and 3D computer-assisted engineering (CAE) French company Dassault Systèmes.

This software provides advanced technology for mechanical surfaces \& BIW. It provides tools for completing product definitions, including functional tolerances and kinematic definitions.

\section{ANALYTCAL PROCEDURE}

\section{A. CAD Modeling}

In this analysis, the CATIA V5R21 is been used to carried out an FEA stress analysis on a camshaft. The 3D camshaft model was generated and analyzed. The model had been created in the pre-processor using the same software suite. It is to ensure smoothness in the analysis because most of the process is using the mutual 
software suite. Geometric features like holes, grooves and corners as well as the local plasticity and high cycle fatigue behavior are taken in to considerations. It will determine the conditions of the failure so that the failure can be avoided.

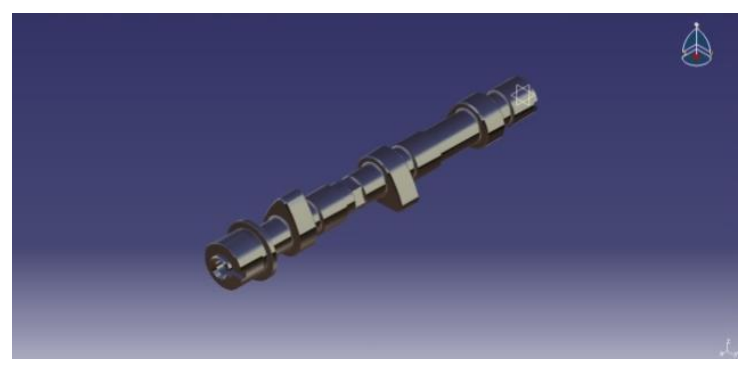

Fig 2: CAD Modeling Generated

\section{B. Applying Mesh}

Mesh generation is the process of dividing the analysis continuum (camshaft modeling) into a number of discrete parts or finite elements. We had to compromise between accuracy \& solution speed done, because the finer the mesh, the better are the results, but also longer is the analysis time. With useful tools embed in the software-suite; the mesh refinement is becoming even easier and mutual. The mesh is created automatically by using a mesh engine. The only requirement is to define the mesh density along the model's edges and corners.

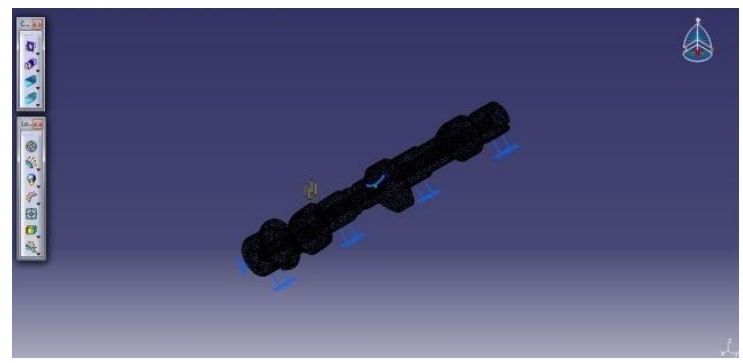

Fig 3: FEA Mesh Modeling Generated

\section{Apply loads and Boundary conditions}

Some types of loads are usually used for analytical models. Load can be used at one dot, edge, and surface or on a complete body. The load must be in the same unit as the geometry of the model and the nature of the specified material. The boundary state of the structure is usually zero. Boundary conditions can be given to act in all directions $(x, y, z)$, or specific directions. The use of proper boundary conditions (BC) is important for solving the exact design problem. At least 1 boundary condition should be used for each model and no loadbearing \& capital analysis burden. Comply with BC briefly.

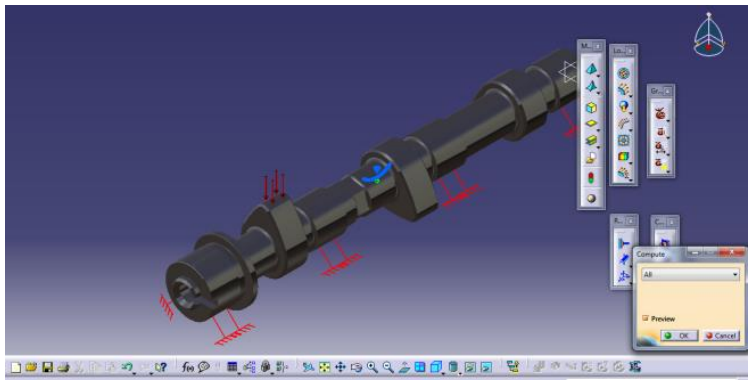

Fig 4: FEA Load Modeling Generated

\section{Solution}

This part is generally done fully automatic. The FE (Finite element) solver had logically divided into 3 main parts, the pre-solver, the mathematical-engine, $\&$ the post-solver. The pre-solver reads in the model made by the preprocessor and formulates the mathematical representation of the model. All parameters defined in the preprocessing stage are used for this analysis. After all the data is been transferred than the solver proceeds to form the element-stiffness matrix for the problem. The processor is also known as the mathematical-engine which calculates the result (displacement, stress and pressures, etc.).The results are then returned to the solver. The post-solver is used to calculate displacement, stress and pressures, etc. for each node and key point.

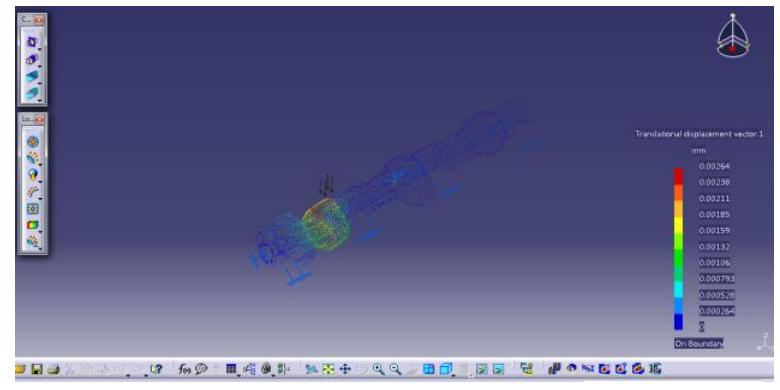

Fig 5: FEA Analysis on Displacement Generated

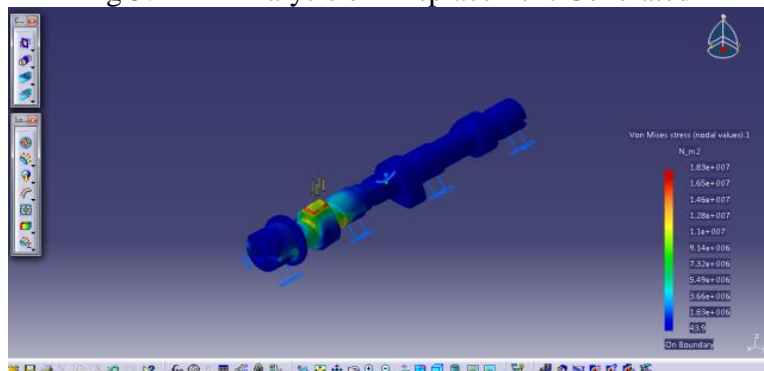

Fig 6: FEA Analysis on Stress Generated 


\section{Finite Element Analysis}

In this section we will take more intimate look at element finite space. This will determine the sub-space for our analysis. In this case we will define a finite continuous and functioning dimension space. We want to estimate settlement in the context of this space. Space finite element built from a set of finite elements, under a sub-channel of the domain.

Sub-interval built into partition of;

$x 0<x 1<x 2<x 3<\ldots<x_{n}$

Where $x 0=0$ and $x n=1$.

Once we partitioned the domain, we need to set one set the function / element.

Need to remind that we can build all the finite elements dimension space uses a set of basic functions on the subinterval.

We will call this element as the element of 'finite element'. The space that forms these elements the base is called space finite element that show the properties of finite elements as shown [25].

Elements up to;

Let $K c R n$ will be put into closed sets that are closed with a borderless and smart interior smooth border (domain element) [26].

Let $\mathrm{P}$ be the dimension space $\mathrm{n}$ function in $K$ (space form function)

Let $N=(N 1, N 2, \ldots \ldots, N)$ is the basis for the set of node $\mathrm{P} 0$ variables.

We can call $(K, P, N)$ as the finite element.

The finite element is here at $R n$. Because we work in the following $R l$, it is important to describe the role of finite elements and finite elements space.

\section{CALCULATION}

Let $K=[0 ; 1]$,

$\mathrm{P}$ is a linear polynomial set, and;

$$
\begin{gathered}
N=\left(N_{l} ; N_{2}\right), \\
\text { Where } N_{I}(v)=v(0) \\
\text { and } N_{2}(v)=v(1) \\
\text { for all } v 2 P .
\end{gathered}
$$

Then $(K ; P ; N)$

The finite element and the base node consists of;

$$
\phi_{1}(x)=1-x \text {, and } \phi_{2}(x)=x .
$$

This is a 1-dimensional Lagrange element.

More generally, let the domain $[0 ; 1]$ is divided in such a way that $0=x_{0}<x_{1} \ldots .<x_{n}=1$, and let $S_{n}$ be a function vector space such Function vector space that;

$$
\text { Vspace }=v \varepsilon C 0(|0 ; 1|), v \mid\left[x_{i} ; x_{i}+1\right]
$$

Is a linear polynomial, for $i=1 ; \ldots ; n$, and $v(0)=0$. Consider the following roofs function:

$$
\phi 1(x)=\left\{\begin{array}{ccc}
\frac{x-x i-1}{h i} & \text { for } x i-1 \leq x \leq x i \\
\frac{x i+1-x}{h i+1} & \text { for } x i \leq x \leq x i+1 \\
0 & \text { for otherwise }
\end{array}\right.
$$

For this function,

$h_{i}=x_{i}-x_{i}-1$ is the size of the fixed interval, $x_{i} 2[0 ; 1]$ with $0=x_{0}<x_{1}<\ldots<x_{n}=1$.

Generally $\mathrm{h}$ should be small. We should notice that the domain is closed and limited by functionality.

$\phi_{i}\left(x_{i}-1\right)=0$,

The same applies to $x_{i}+1$.

This is the domain element;

The shape functions are;

$$
\begin{aligned}
& \text { Fshape }=\frac{x-x i-1}{h i} \text { for } x i-1 \leq x \leq x i \\
& \text { Fshape }=\frac{x i+1-x}{h i+1} \text { for } x i \leq x \leq x i+1
\end{aligned}
$$

Eventually the set of all such functions form the basis for space finite elements. The function is;

$$
\{\phi i: i=1 ; 2 ; \ldots . n\}
$$

The function is linear free and includes finite element space Sn.

\section{RESULT AND DISCUSSION}

In this Project, the camshaft model was created by CATIA V5 R21 software. Then, the model created by CATIA was had been analyze within the same software to ensure their mutuality data. 


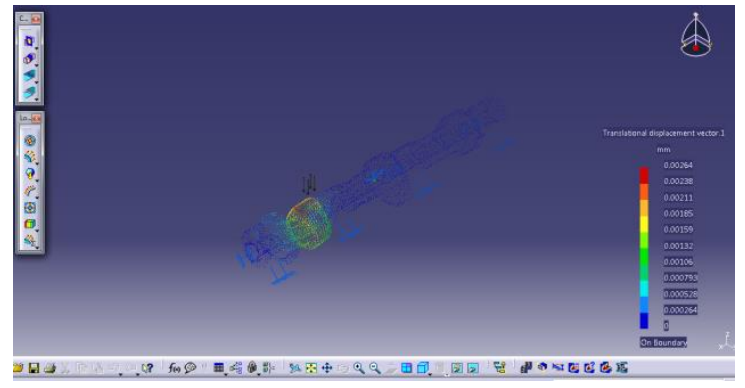

Fig 7: Analysis on Steel Displacement Generated

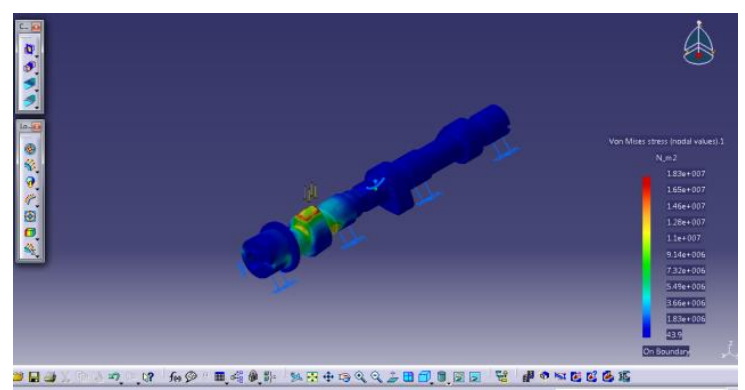

Fig 8: Analysis on Steel Stress Generated

From the figure above, we can see that steel as a reference has stress distribution ranging from $1.83 \mathrm{e}+006$ (N_m2) to $1.83 \mathrm{e}+007$ (N_m2). The steel also have a Translational Displacement ranging from $0.00264(\mathrm{~mm})$ to $0.000264(\mathrm{~mm})$.

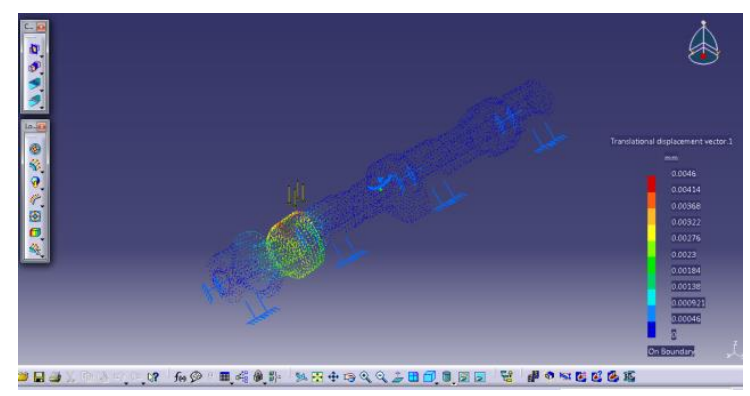

Fig 9: Analysis on Titanium Displacement Generated

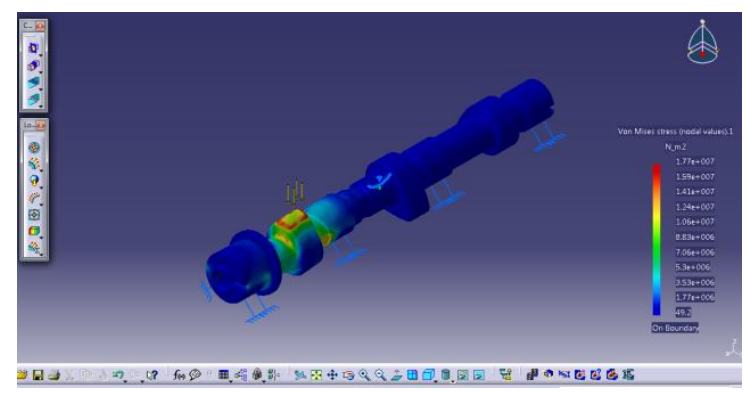

Fig 10: Analysis on Titanium Stress Generated

While for titanium, we can see that the stress distribution ranging from $1.77 \mathrm{e}+006$ (N_m2) to $1.77 \mathrm{e}+007$ (N_m2).
The titanium also have a Translational Displacement ranging from $0.00046(\mathrm{~mm})$ to $0.0046(\mathrm{~mm})$.

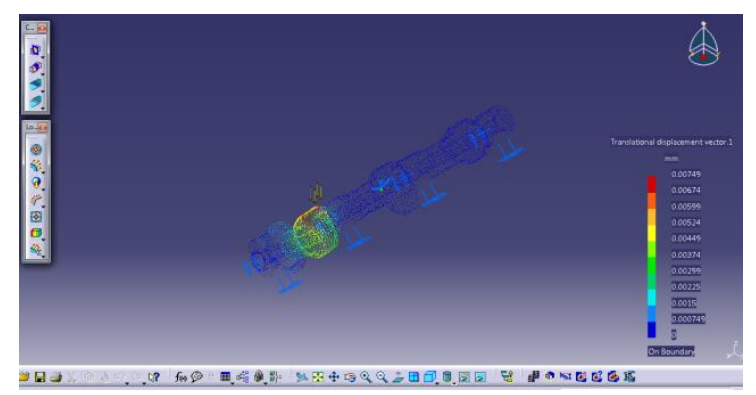

Fig 11: Analysis on Aluminum Displacement Generated

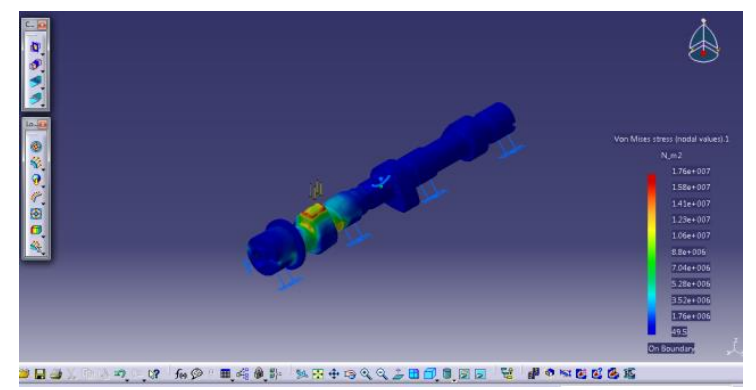

Fig 12: Analysis on Aluminum Stress Generated

Further for aluminums, we can see that the stress distribution ranging from $1.76 \mathrm{e}+006$ (N_m2) to 1.76e+007 (N_m2). The aluminums also have a Translational Displacement ranging from 0.000749 (mm) to 0.00749 (mm).

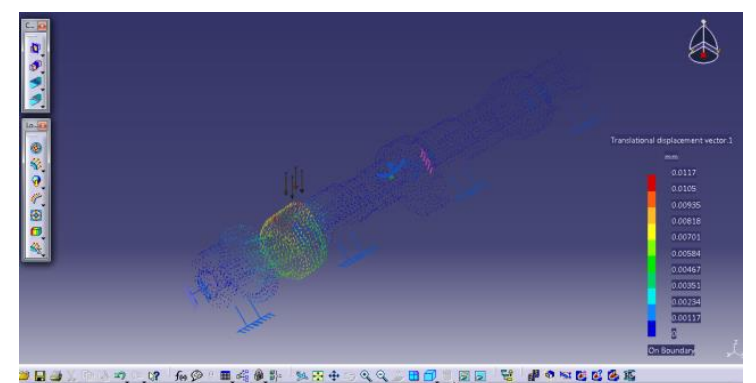

Fig 13: Analysis on Magnesium Displacement Generated

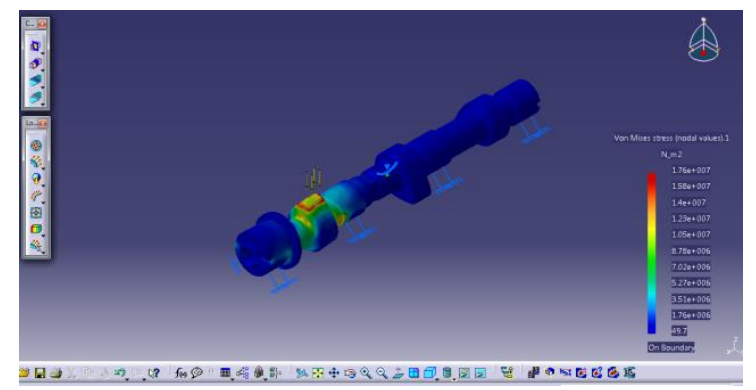

Fig 14: Analysis on Magnesium Stress Generated 
Finally for magnesium, we can see that the stress distribution ranging from $1.76 \mathrm{e}+006$ (N_m2) to 1.76e+007 (N_m2). The aluminums also have a Translational Displacement ranging from $0.00117(\mathrm{~mm})$ to 0.00749 (mm).

Referred to previous data and figure, the Stress Distribution (Von Mises), Translational displacement and data related had been concluded in a table below;

Table 1: Comparison of Material Characteristics.

\begin{tabular}{|c|c|c|c|c|}
\hline & 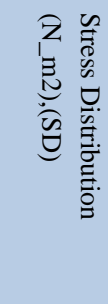 & 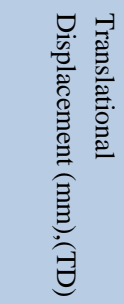 & 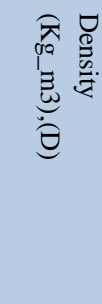 & 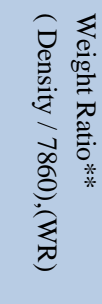 \\
\hline Steel & $\begin{array}{l}1.83 \\
\mathrm{e}+007\end{array}$ & 0.00264 & 7860 & 1.000 \\
\hline Titanium & $\begin{array}{l}1.77 \\
\mathrm{e}+007\end{array}$ & 0.00460 & 4460 & 0.567 \\
\hline Aluminium & $\begin{array}{l}1.76 \\
\mathrm{e}+007\end{array}$ & 0.00749 & 2710 & 0.345 \\
\hline Magnesium & $\begin{array}{l}1.76 \\
e+007\end{array}$ & 0.01170 & 1798 & 0.229 \\
\hline
\end{tabular}

**Weight Ratio = Material density/ Steel density.

We could also present the data clearer in a Graph form as below. The Graph related is;

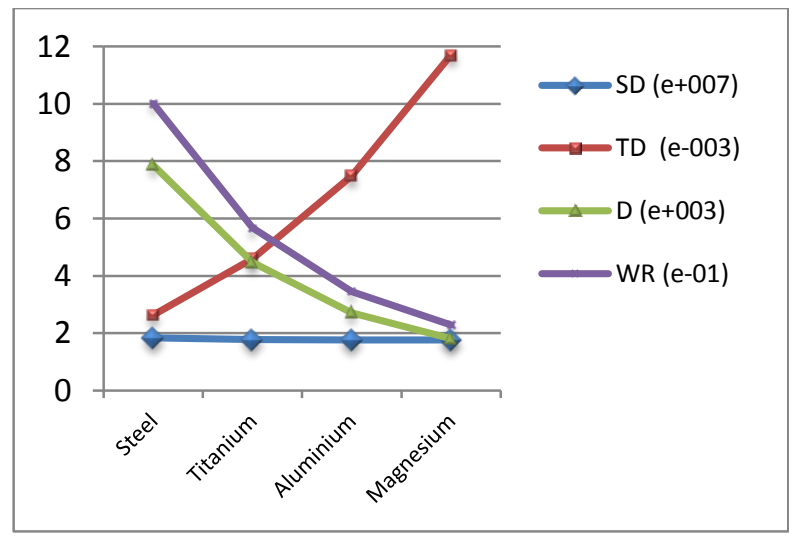

Fig 15: Graph Result FEA for 4 metals.

\section{CONCLUSION}

Referred from the data above, we know that the maximum deformation appears on the steel are 0.00264 (mm). For this analysis, we take the steel material as a reference as a good material for cam shaft. Cause of that, we could say that the worst material (highest translational displacement) are magnesium. For stress distribution, we could say that magnesium and aluminum is the worst material (lowest stress distribution) for cam production.

By referring to the minimum specification of cam properties, we could say that all material are qualified for cam production because all material translational stress distribution are low that $0.05000(\mathrm{~mm})$. Those materials also can reduce the weight of cam product.

But if look at a holistic approach, we could see that all material have their advantage and disadvantages for the cam production. For all 3 types of material, we could say that they can reduce the weight of cam product. But specifically, titanium should be compatible price for current value, for aluminum \& magnesium, they could be alloyed with more strength $\&$ hardness to make sure that they can compete with other material toughness and strength.

\section{REFERENCES}

[1] Kimes, Beverly Rae (2007). Walter L Marr: Buick's Amazing Engineer. Racemaker Press, p. 40-42. ISBN 0976668343.

[2] https://www.carcustomonline.com/22-4110-0-EMPICAM-430L-284D-p/22-4110-0.htm.

[3] Pulkrabek, Willard W. (1997). Engineering Fundamentals of the Internal Combustion Engine. Prentice Hall, p. 2-30. ISBN 9780135708545.

[4] Jackson JA, Mehl JP, Neuendorf KKE (eds) 2005, Glossary of Geology, 5th ed., American Geological Institute, Alexandria, ISBN 0-922152-76-4, p. 371.

[5] Brandes EA \& Brook GB (eds) 1998, Light Metals Handbook, Butterworth Heinemann, Oxford, ISBN 0 75063625-4, p. viii

[6] Polmear I 2006, Light Alloys: From Traditional Alloys to Nanocrystals, 4th ed., Butterworth Heinemann, Oxford, ISBN 0-7506-6371-5, p. 1.

[7] Shakhashiri, B. Z. (17 March 2008). "Chemical of the Week: Aluminum" (PDF). SciFun.org. University of Wisconsin. Archived (PDF) from the original on 9 May 2012. Retrieved 4 March 2012.

[8] Singh, Bikram Jit (2014). RSM: A Key to Optimize Machining: Multi-Response Optimization of CNC Turning with Al-7020 Alloy. Anchor Academic Publishing (aap_verlag). ISBN 9783954892099. p. 13-21

[9] Hihara, Lloyd H.; Adler, Ralph P. I.; Latanision, Ronald M. (2013-10-23). Environmental Degradation of Advanced and Traditional Engineering Materials. CRC Press. ISBN 9781439819272. p. 17-22.

[10] Abundance and form of the most abundant elements in Earth's continental crust" (PDF). Retrieved 15 February 2008. [11] Anthoni, J Floor (2006). "The chemical composition of seawater". seafriends.org.nz.

[12] "Titanium". Encyclopædia Britannica. 2006. Retrieved 29 December 2006. 
[13] Lide, D. R., ed. (2005). CRC Handbook of Chemistry and Physics (86th ed.). Boca Raton (FL): CRC Press. ISBN 08493-0486-5. p. 31-35.

[14] Krebs, Robert E. (2006). The History and Use of Our Earth's Chemical Elements: A Reference Guide (2nd ed.). Westport, CT: Greenwood Press. ISBN 0-313-33438-2. p. 5256.

[15] Donachie 1988, p. 11

[16] Barksdale 1968, p. 738

[17] "Titanium". Columbia Encyclopedia (6th ed.). New York: Columbia University Press. 2000-2006. ISBN 0-7876-5015-

3. Archived from the original on 18 November 2011.

[18] Barbalace, Kenneth L. (2006). "Periodic Table of Elements: Ti - Titanium". Retrieved 26 December 2006.

[19] Narayan, K. Lalit (2008). Computer Aided Design and Manufacturing. New Delhi: Prentice Hall of India. ISBN 812033342X.p. 3-4.

[20] Duggal, Vijay (2000). Cadd Primer: A General Guide to Computer Aided Design and Drafting-Cadd, CAD. Mailmax Pub. ISBN 978-0962916595. p. 43-46.
[21] Madsen, David A. (2012). Engineering Drawing \& Design. Clifton Park, NY: Delmar. p. 10. ISBN 1111309574. [22] Farin, Gerald; Hoschek, Josef; Kim, Myung-Soo (2002). Handbook of computer aided geometric design [electronic resource]. Elsevier. ISBN 978-0-444-51104-1. p. 24-31.

[23] Pottmann, H.; Brell-Cokcan, S. and Wallner, J. (2007) "Discrete surfaces for architectural design" Archived 2009-0812 at the Wayback Machine., in Curve and Surface Design, Patrick Chenin, Tom Lyche and Larry L. Schumaker (eds.), Nashboro Press, ISBN 978-0-9728482-7-5.p. 213-234.

[24] Daryl L. Logan (2011). A first course in the finite element method. Cengage Learning. ISBN 9780495668251.

[25] Jacques-Louis Lions. Casinapioiv.va. Retrieved on 9 May 2016.

[26] Brenner, S. and Scott, L. R., The Mathematical Theory of Finite Element Methods, 3rd Ed., Springer, New York, 2008. p. $83-85$. 